\title{
Effects of Conventional Laser Assisted In-Situ Keratomileusis (Lasik) on Spherical Aberrations and Contrast Sensitivity in the Myopic Eyes
}

\author{
Dr. Praful Chaudhary ${ }^{1}$, Dr. Kalyani Pawar Chaudhary ${ }^{2}$ \\ ${ }^{1}$ MBBS, DO, DNB (Ophthalmology) \\ ${ }^{2}$ MBBS, DGO, DNB (OBGY)
}

\begin{abstract}
Background: LASIK is the new surgical procedure for the correction of eye's refractive error. It helps in reducing the patient's dependence on glasses \&/or contact lenses. But it also increases the spherical aberrations of the eye and reduces contrast sensitivity. Aim: To investigate the changes in spherical aberrations, contrast sensitivity \& spherical equivalent of the myopic eyes caused by conventional LASIK. Method: A prospective, observational study was done in patients with treatable myopic refractive error after undergoing conventional LASIK. Total 29 patients with 56 myopic eyes undergoing LASIK were recruited over a period of six months from Jan 2011 to June 2011 and were followed up for a period of 6 months. Results: After LASIK, mean logMAR visual acuity at 1, 3, and 6 was -0.096 which was significantly more as compared to baseline. Pre-operatively mean spherical equivalent was -4.59 . There was statistically significant reduction in the mean spherical equivalent post-operatively at 1,3 \& 6 months. Spherical aberration was significantly increased after LASIK (2.71 folds at 1 month, 2.38 fold at 3 months and 2.19 folds at 6 months). Contrast sensitivity (CS) was significantly reduced one month post LASIK for the higher spatial frequencies of 12 and 18 cpd. Conclusion: Conventional LASIK significantly increases the postoperative spherical aberrations at 1, 3, and 6 months. It causes significant reduction in CS values at higher frequencies, which recovers to the preoperative levels at 6 months. After LASIK contrast sensitivity at lower spatial frequencies are not significantly altered.
\end{abstract}

Keywords: LASIK, Spherical aberrations, Contrast sensitivity

\section{Introduction}

Over recent years, a number of surgical procedures in ophthalmology have offered an alternative for glasses or contact lenses. One of the most popular is Laser Assisted inSitu Keratomileusis (LASIK).

The surgical objective of LASIK is to change the corneal curvature and, in turn, alter or reduce the eye's refractive error. As a result, the patient's dependence on glasses and/or contact lenses is reduced.

Refractive corneal surgery mainly focuses on the correction of spherocylindrical errors as the most apparent and disturbing optical aberrations of the human eye. Unfortunately, these corrections are accompanied by a significant increase in higher-order optical aberrations (such as spherical and coma aberration) and decrease in contrast sensitivity.

The term keratomileusis used by Barraquer comes from the Greek words for "cornea" (kerato) and "to carve" (mileusis). Laser in situ keratomileusis(LASIK), which combines keratomileusis with excimer laser stromal ablation., has become the most popular refractive procedure performed today because of its safety, efficacy, quick visual recovery and minimal patient discomfort.

Laser in situ keratomileusis (LASIK) is one of the most popular techniques for the correction of refractive errors. The most common indication for LASIK surgery in the present times is myopia, although it is also being increasingly utilized to treat hypermetropia and astigmatism. $^{27-33}$

Laser-in-situ keratomileusis (LASIK) has been used to treat myopia ranging from -1 to -29 dioptres $^{39}$ It is important to remember that the amount of myopic correction possible in a particular patient is determined by the central corneal pachymetry and correction of myopic refractive errors in excess of -12 dioptres may not be possible if the central pachymetry is less than $500 \mu \mathrm{m}$.

Myopia is the most common type of refractive error. In myopia, the secondary focal point is anterior to the retina. In other words, the refractive power of the eye is greater than that required for emmetropia; parallel rays of light entering the eye are in focus at a location in the vitreous, rather than on the retina. LASIK corrects myopia by removing tissue in the center of the cornea, thereby flattening the cornea and decreasing the refractive power of the eye. ${ }^{23}$

Previous studies have demonstrated that laser in situ keratomileusis (LASIK) significantly increases higher-order wavefront aberrations of the eye $e^{1-9}$, mainly spherical aberrations $^{9-13}$ and reduces contrast sensitivity. ${ }^{13-22}$ Hence, this study was carried out to investigate the changes in spherical aberrations, contrast sensitivity \& spherical equivalent of the myopic eyes caused by conventional LASIK.

\section{Material \& Methods}

A prospective, observational study was done in patients with treatable myopic refractive error after undergoing 


\section{International Journal of Science and Research (IJSR) \\ ISSN (Online): 2319-7064}

Index Copernicus Value (2013): 6.14 | Impact Factor (2014): 5.611

conventional LASIK at Bombay City Eye Institute \& Research Centre, Mumbai. All patients undergoing LASIK for myopia were recruited over a period of six months from Jan 2011 to June 2011 and were followed up for a period of 6 months. So, our sample size was 56 myopic eyes of 29 patients who underwent conventional LASIK during the mentioned study period and were followed up for 6 months to study changes in spherical aberrations of the eye after the LASIK procedure.

\section{Inclusion criteria}

1) Patients aging more than 18 years

2) Patients having treatable refractive error (Myopia-1 to-10 Diopter)

3) Patient should have a pachymetry of more than or equal to 500 microns

4) Patients should have a clear cornea with no other ocular pathology

5) Patients willing to participate in this study

6) Ability and willingness to provide informed consent

All patients were clinically evaluated for the visual acuity (uncorrected and best corrected), retinoscopy, contrast sensitivity testing, corneal topography, wave front analysis with Hartmann-Shack wavefront analyzer, anterior segment optical coherence tomography (OCT), ultrasonic pachymetry and dilated retinal evaluation.

All cases were done by same experienced corneal surgeon under same surgical conditions. Clearance was obtained from the institutional ethics committee.

A written informed consent was obtained from all patients, after having explained to them the nature of the treatment, the procedure being performed, and the possible consequences therein.

The following parameters were recorded pre-operatively:

1) Best corrected visual acuity- Refraction assessed objectively by retinoscopy and autorefractometer, and then confirmed subjectively, further recorded by Snellen's acuity charts and equivalent logMAR values.

2) Contrast sensitivity testing- The CSV-1000E chart presents vertical sine wave gratings at four spatial frequencies - $3,6,12$, and $18 \mathrm{cyc} / \mathrm{deg}$ - and each spatial frequency has eight different levels of contrast. Each row consists of eight pairs of circular patches, including sine waves of a single spatial frequency. In each pair, one patch presents a grating, and the other patch is blank. The patient was asked to identify which patch had a grating, and the contrast level of the last correct response was defined as the contrast threshold in logarithmic values for each frequency.

3) Wave Front Analysis - this was done in all patients to see the aberrations of the eyes mainly spherical aberrations $\left(\mathrm{Z}_{4}{ }^{0}\right)$ with using Hartmann-Shack wavefront analyzer (WASCA, Carl Zeiss Meditec AG07740 Jena, Germany).

4) Corneal thickness

a) Anterior Segment OCT-was done in all patients to see the global pachymetry values of both the eyes. (Visante, Carl Zeiss Meditec Inc. Dublen, CA, USA),

b) Ultrasonic Pachymetry (Pachymate) - was done to see the thickness at the centre of the cornea.
5) Corneal topography- Simulated Keratometry values were determined using the ATLAS Corneal Topography System featuring MasterVue Software, Zeiss.

6) Slit lamp evaluation- A detailed clinical evaluation of anterior segment was done, looking out for clinical signs, using the Topcon Slit Lamp, Model SL 1E. Intraocular pressure was measured with Goldmann Applanation tonometer.

7) Dilated Retinal Evaluation - a dilated fundus examination was done using an indirect ophthalmoscope (Heine Model D40 Omega 2c) and a Volk +20D lens to look for any retinal holes or tears which were lasered prior to the LASIK procedure.

\section{Surgical Procedure}

- Preoperatively- All patients posted for surgery were given Moxifloxacin eye drops (Vigamox, Texas, USA) four times a day in both eyes for 2 days before surgery.

- Anaesthesia - All the procedures were performed under topical anaesthesia with $0.5 \%$ Proparacaine eye drops.

- Preparation - The eye lashes were removed from the operative field with a sterile sticking tape and draping was done.

- Surgical Technique - Speculum was applied to the lids.The automated microkeratome (Moriaone use-plus SBK head 90 micron head or 130 micron head) suction ring was fixed on the eye. The intraocular pressure was sufficiently raised which was checked by barraquer tonometer. The desired flap of 90 microns or 130 microns was made with the automated one use disposable microkeratome head. The flap was then raised. The bed was dried Excimer laser photoablation was done (Carl Zeiss, Mel 80). The flap was reposited.

- Post operatively - All patients were given Moxifloxacin $0.5 \%$ four times a day for one week, Prednisolone acetate $1 \%$ eye drops four times a day for one week and lubricating eye drops for three months.

- Follow up - Patients were followed up on first postoperative day, at one week, one month, 3 months and 6 months. At each visit visual acuity was noted along with refraction and slit lamp evaluation of the anterior segment. Wave front analysis and contrast sensitivity testing was performed at each visit.

\section{Data Collection Technique and Tools}

All the figures were taken from the study population.

Results of subjective refraction were collected and converted to spherical equivalent (SE) values for analysis. Visual acuity was measured in terms of LogMAR values. All contrast sensitivity data were transformed to logarithmic units and $\log$ contrast sensitivity values are used for the analysis.

\section{Data Analysis}

All data are recorded as the mean \pm SD. Statistical analysis was performed using SPSS 15.0 software. The data was analyzed using the Student's paired T test on outcome parameters such as $\log$ MAR visual acuity, spherical equivalent and spherical aberration. Contrast sensitivity data (log contrast sensitivity values) was analyzed individually, with multiple comparisons using Student's paired ' $t$ ' test and 


\section{International Journal of Science and Research (IJSR) \\ ISSN (Online): 2319-7064}

Index Copernicus Value (2013): 6.14 | Impact Factor (2014): 5.611

Wilcoxon signed ranked test.\& p value of less than 0.05 was considered statistically significant.

\section{Results}

We studied 56 eyes of 29 patients, who underwent an uneventful LASIK. This study included 29 patients in which 10 were males and 19 were females. Out of the 56 operated eyes, proportion of right \& left eyes was equal (Table 1). The average age of patients was 27.62 years (range, 19 - 46 years).

Average simulated keratometry value was $44.44 \pm 1.68 \mathrm{D}$ (range, 40.87 to 47.87 ) while average ultrasound central corneal pachymetry was $556.35 \pm 33.35$ (range, 500 to 624 ) (Table 2).

Table 3 shows the changes in visual acuity after LASIK (logMAR values). After LASIK, mean logMAR visual acuity at 1,3 , and 6 was -0.096 . LASIK significantly improved visual acuity at 1,3 and 6 months after the procedure compared to the best corrected visual acuity at baseline.

Pre-operatively mean spherical equivalent was -4.59 . There was statistically significant reduction in the mean spherical equivalent post-operatively at $1,3 \& 6$ months. After LASIK, mean spherical equivalent at 1,3 , and 6 was -0.022 , -0.002 and -0.009 respectively. LASIK significantly reduced the refractive error. $94.64 \%$ of eyes were within $0.25 \mathrm{D}$ of the intended correction (Table 4).

Table 5 shows the changes in spherical aberration. Spherical aberration $(Z 4,0)$ was significantly increased after LASIK ( 2.71 folds at 1 month, 2.38 fold at 3 months and 2.19 folds at 6 months), After LASIK, mean spherical aberration at 1 , 3 , and 6 months was $-0.57,-0.50$, and -0.46 respectively. Statistically significant difference was found at 1 st month $(\mathrm{p}=0.00)$, 3rd month $(\mathrm{p}=0.00)$ and 6th month $(\mathrm{p}=0.00)$.

Contrast sensitivity (CS) was not significantly altered for lower spatial frequencies of 3 and $6 \mathrm{cpd}$ (cycles per degree) throughout the study period. It was significantly reduced one month post LASIK for the higher spatial frequencies of 12 and $18 \mathrm{cpd}$ ( $\mathrm{p}$ value 0.08 and 0.04 respectively). At 3 months, CS for 12 cpd spatial frequency continued to remain significantly reduced whereas that for $18 \mathrm{cpd}$ spatial frequency recovered. At 6 months, the values were comparable to the pre-operative levels for all spatial frequencies. Paired $\mathrm{T}$ test and Wilcoxon signed ranks test was used (Table 6).

\section{Discussion}

As refractive surgery evolves, laser in situ keratomileusis (LASIK) has gained widespread popularity as the procedure of choice to correct refractive errors. LASIK can reduce refractive error and improve uncorrected visual acuity, but several problems must be resolved regarding postoperative ocular aberrations and visual function.

Previous studies have demonstrated that laser in situ keratomileusis (LASIK) significantly increases higher-order wavefront aberrations of the eye $\mathrm{e}^{1-9}$, mainly spherical aberrations $^{9-13}$ and reduces contrast sensitivity. ${ }^{13-22}$

Oshika et $\mathrm{al}^{1}$ found an increase of $3 \mathrm{rd}$ and higher order corneal aberrations (2.7-fold for LASIK and 2.3-fold for PRK), with respect to preoperative values in the same eyes. Nayori Yamane-et al. ${ }^{13}$ also concluded that conventional LASIK significantly increases ocular higher-order aberrations, which compromise the postoperative contrast sensitivity function. Loukotova $\mathrm{V}$ et al. ${ }^{53}$ concluded that the after conventional LASIK treatment induction of higher order aberrations was twice as much and was directly correlated to the degree of the laser correction. The spherical aberration was four-times higher comparing to the preoperative values and was independent to the level of the initial refractive error.

In our study we found that conventional LASIK significantly induced spherical aberration, in good agreement with previous studies $^{1-13}$

Perez-Santonja et al. ${ }^{15}$ stated that although LASIK decreased contrast sensitivity values at low and intermediate spatial frequencies for 1 month after surgery, these values rapidly returned to the preoperative values at 3 months. The improvement at certain frequencies at 6 months suggests that LASIK can improve the quality of vision in eyes with moderate and high myopia. Chan JW et al. ${ }^{20}$ monitored contrast sensitivity in 41 LASIK patients for 1 year. They found post-LASIK non-permanent depression in contrast sensitivity, which was probably due to optical factors. Chan et al. also found that recovery of contrast sensitivity after LASIK took at least 6 months.

In our study we noticed that contrast sensitivity (CS) was not significantly altered for lower spatial frequencies of 3 and 6 cpd (cycles per degree) throughout the study period. It was significantly reduced one month post LASIK for the higher spatial frequencies of 12 and $18 \mathrm{cpd}$. At 3 months, CS for $12 \mathrm{cpd}$ spatial frequency continued to remain significantly reduced whereas that for $18 \mathrm{cpd}$ spatial frequency recovered. At 6 months, the values were comparable to the pre-operative levels for all spatial frequencies.

\section{Conclusion}

1) Conventional LASIK significantly increases the postoperative spherical aberrations at 1, 3, and 6 months.

2) Conventional LASIK causes significant reduction in contrast sensitivity (CS) values at higher frequencies (12 and 18 cycles per degree) for 1 month. At 3 months postoperatively; the decrease in CS values is significant only at spatial frequency 12 cycles per degree. Although these contrast sensitivity values rapidly recovers to the preoperative levels at 6 months. After LASIK contrast sensitivity at lower spatial frequencies of 3 and $6 \mathrm{cpd}$ (cycles per degree) are not significantly altered.

Limitations of our study were small sample size, larger population based study is required to confirm the changes in contrast sensitivity and spherical aberrations after conventional LASIK on myopic eyes. Follow up duration should have been longer to study the long term effects of the 


\section{International Journal of Science and Research (IJSR) \\ ISSN (Online): 2319-7064}

Index Copernicus Value (2013): 6.14 | Impact Factor (2014): 5.611

LASIK on contrast sensitivity function and spherical aberration. Also, we did not study the relation between the changes in contrast sensitivity and spherical aberrations. So, further studies are required to study the correlation between these two parameters.

So far, refractive surgery has concentrated on the reduction of spherical and cylindrical defocus, and much less attention has been directed towards the higher-order aberrations like spherical and coma aberrations and decline of contrast sensitivity function. Hence, based on our study findings we recommend that LASIK is an effective and safe procedure for treating myopic refractive error. In consideration of quality of life and vision in patients after LASIK, further attention should be paid to the influence of surgery on higher-order aberration and visual function in detail, rather than on Snellen visual acuity alone. Wave front guided or customized LASIK should be promoted to avoid loss of or achieve an increase in visual acuity after LASIK. Further studies on larger dataset are required to confirm the occurrence and magnitude of such changes.

\section{References}

[1] Oshika T, Klyce SD, Applegate RA, Howland HC, El Danasoury MA. Comparison of corneal wavefront aberrations after photorefractive keratectomy and laser in situ keratomileusis. Am J Ophthalmol.1999;127:1-7.

[2] Marcos S, Barbero S, Llorente L, Merayo-Lloves J. Optical response to LASIK surgery for myopia from total and corneal aberration measurements. Invest Ophthalmol Vis Sci. 2001;42:3349-3356.

[3] Mrochen M, Kaemmerer M, Mierdel P, Seiler T. Increased higherorder optical aberrations after laser refractive surgery; a problem of subclinical decentration. J Cataract Refract Surg. 2001;27:362-369.

[4] Oshika T, Miyata K, Tokunaga T, et al. Higher order wavefront aberrations of cornea and magnitude of refractive correction in laser in situ keratomileusis. Ophthalmology. 2002;109:1154-1158.

[5] Miller JM, Anwaruddin R, Straub J, Schwiegerling J. Higher order aberrations in normal, dilated, intraocular lens, and laser in situ keratomileusis corneas. J Refract Surg. 2002;18:S579-S583.

[6] Pallikaris IG, Kymionis GD, Panagopoulou SI, Siganos CS, Theodorakis MA, Pallikaris AI. Induced optical aberrations following formation of a laser in situ keratomileusis flap. J Cataract Refract Surg. 2002; Vol 28:1737-1741.

[7] Mok KH, Lee VW. Effect of optical zone ablation diameter on LASIK-induced higher order optical aberrations. J Refract Surg.2005;Vol 21:141-143.

[8] Kohnen T, Buhren J, Kuhne C, Mirshahi A. Wavefrontguided LASIK with the Zyoptix 3.1 system for the correction of myopia and compound myopic astigmatism with 1-year follow-up: clinical outcome and change in higher order aberrations. Ophthalmology.2004;111:2175-2185.

[9] Moreno-Barriuso E, Lloves J, Marcos S, Navarro R, Llorente L, Barbero S. Ocular aberrations before and after myopic cornealrefractive surgery: LASIK-induced changes measured with laser raytracing. Invest Ophthalmol Vis Sci 2001May;42(6):1396-403.
[10] Buzzonetti L, Iarossi G, Valente P, Volpi M, Petrocelli G,Scullica L. Comparison of wavefront aberration changes in the anterior corneal surface after laserassisted subepithelial keratectomy and laser in situ keratomileusis: preliminary study. J Cataract Refract Surg 2004;30:1929-1933

[11] Chalita MR, Chavala S, Xu M, Krueger RR. Wavefront analysis in post-LASIK eyes and its correlation with visual symptoms, refraction, and topography. Ophthalmology 2004; 111:447-453

[12] Chalita MR, Xu M, Krueger RR. Correlation of aberrations with visual symptoms using wavefront analysis in eyes after laser in situ keratomileusis. J Refract Surg 2003; 19:S682-S686

[13] Yamane N, Miyata K, Samejima T, et al. Ocular higherorder aberrations and contrast sensitivity after conventional laser in situ keratomileusis. Invest Ophthalmol Vis Sci. Nov 2004; Vol 45:3986-989.

[14] Wang Z, Chen J, Yang B. Comparison of laser in situ keratomileusis and photorefractive keratectomy to correct myopia from -1.25 to -6.00 diopters. J Refract Surg. 1997; 13:528-534.

[15] Pe'rez-Santonja JJ, Sakla HF, Alio JL. Contrast sensitivity after laser in situ keratomileusis. J Cataract Refract Surg. 1998;24:183-189.

[16] Carr JD, Stulting RD, Sano Y, Thompson KP, Wiley W, Waring GO3rd. Prospective comparison of single-zone and multizone laser in situ keratomileusis for the correction of low myopia. Ophthalmology.1998;105:1504-1511.

[17] Holladay JT, Dudeja DR, Chang J. Functional vision and corneal changes after laser in situ keratomileusis determined by contrast sensitivity, glare testing, and corneal topography. J Cataract Refract Surg. May 1999; Vol 25:663-669.

[18] Mutyala S, McDonald MB, Scheinblum KA, Ostrick MD, Brint SF, Thompson H. Contrast sensitivity evaluation after laser in situ keratomileusis. Ophthalmology. 2000;107:1864-1867.

[19] Nakamura K, Bissen-Miyajima H, Toda I, Hori Y, Tsubota K. Effect of laser in situ keratomileusis correction on contrast visual acuity. J Cataract Refract Surg. 2001;27:357-361.

[20] Chan JW, Edwards MH, Woo GC, Woo VC. Contrast sensitivity after laser in situ keratomileusis, one-year follow-up. J Cataract Refract Surg. 2002;28:1774-1779.

[21] Lee YC, Hu FR, Wang IJ. Quality of vision after laser in situ keratomileusis: influence of dioptric correction and pupil size on visual function. J Cataract Refract Surg. 2003;29:769-777.

[22] Pop M, Payette Y. Correlation of wavefront data and corneal asphericity with contrast sensitivity after laser in situ keratomileusis for myopia. J Refract Surg. 2004;20(suppl):S678 -S684.

[23] Dimitri T. Azar, editor. LASIK Fundamentals, Surgical Techniques, and Complications textbook, ISBN: 08247-0797-4, Copyright (C) 2003 by Marcel Dekker, pages 1-5.

[24] Gregory L. Skuta, Louis B. Cantor, Jayne S. Weiss, Basic and Clinical Science Course, American Academy of Ophthalmology, Refractive Surgery, Section 13, 2009-2010, p.14-17. 


\section{International Journal of Science and Research (IJSR) \\ ISSN (Online): 2319-7064}

Index Copernicus Value (2013): 6.14 | Impact Factor (2014): 5.611

[25] Myron yanoff, Jay S. Duker, James J. Augsburger, Editors, Yanoff \& Duker: Ophthalmology textbook, 3rd ed. Contrast sensitivity testing. (C) 2008 Mosby, An Imprint of Elsevier, chapter 2.6.

[26] Vectorvision (Internet), CSV 1000E norms at official website, Available from: http://www.vectorvision.com/html/educationCSV1000 Norms.html

[27] Buratto L, Ferrari M. Indications, techniques, results, limits, and complications of laser in situ keratomileusis. Curr Opin Ophthalmol. 1997; 8(4):59-66.

[28] Mulhern MG, Condon PI, O’Keefe M. Myopic and hyperopic laser in situ keratomileusis retreatments: indications, techniques, limitations, and results. J Cataract Refract Surg. 2001;27(8):1278-87.

[29] Gimbel HV, Levy SG. Indications, results, and complications of LASIK.CurrOpinOphthalmol.1998; 9(4):3-8.

[30] Malecha MA, Holland EJ. Correction of myopia and astigmatism after penetrating keratoplasty with laser in situ keratomileusis. Cornea. 2002;21 (6):564-69.

[31] Bains RA, Perreault S, Braun DA, Penno EEA, Gimbel HV. Patient Education, Assessment and Informed Consent. In: Refractive Surgery: A manual of principles and practice. Ed. Gimbel HV, Penno EEA. SLACK Inc. Thorofare, NJ. 2000; 23-38.

[32] Bains RA, Penno EEA, Gimbel HV. Myopia, Hyperopia and Astigmatism In: Refractive Surgery: A manual of principles and practice. Ed. Gimbel HV, Penno EEA. SLACK Inc. Thorofare, NJ. 2000; 17-22.

[33] Bains RA, Penno EEA, Gimbel HV. Laser in-situ keratoileusis In: Refractive Surgery: A manual of principles and practice. Ed. Gimbel HV, Penno EEA. SLACK Inc. Thorofare, NJ. 2000; 127-57, 2000.

[34] Guell JL, Gris O, de Muller A, Corcostegui B. LASIK for the correction of residual refractive errors from previous surgical procedures. Ophthalmic Surg Lasers. 1999; 30(5):341-49.

[35] Jain S, Ou R, Azar DT. Monovision outcomes in presbyopic individuals after refractive surgery. Ophthalmology. 2001; 108(8):1430-33.

[36] Sippel KC, Jain S, Azar DT. Monovision achieved with excimer laser refractive surgery. IntOphthalmolClin. 2001;41(2):91-101.

[37] Boyd BF, Krueger R, Murube J. McDonald M, Wilson S. LASIK in Presbyopia. In: LASIK and Beyond LASIK. Ed. Boyd BF. Highlights of Ophthalmology Intl, Panama, Panama.2001; 427-33.

[38] Avalos-Urzua G, Silva-Lepe A. Presbyopia. In: LASIK and Beyond LASIK. Ed. Boyd BF. Highlights of Ophthalmology Intl, Panama, Panama.2001; 435-448.

[39]Knorz MC, Liermann A, Seiberth V, Steiner H, Wiesinger B. Laser in situ keratomileusis to correct myopia of -6.00 to -29.00 diopters. J Refract Surg 1996; 12(5):575-84.

[40] Rasik B Vajpayee, Namrata Sharma, Samir A Melki, Laurence Sullivan, Editors : Step by Step LASIK Surgery, published in the Taylor \& Francis e-Library, 2006, p.21-31.

[41] Hori-Komai Y, Toda I, Asano-Kato N, Tsubota K. Reasons for not performing refractive surgery. J Cataract Refract Refract Surg 2000; 16(3):368-70
[42] Lafond G, Bazin R, Lajoie C. Bilateral severe keratoconus after laser in situ keratomileusis in a patient with forme frusta keratoconus. J Cataract Refract Surg 2001; 27(7): 1115-18.

[43] Seiler T, QuurkeAW. Iatrogenic keratectasia after LASIK in a case of forme fruste keratoconus. J Cataract Refract Surg 1998; 24(7):1007-09.

[44] Holland SP, Srivannaboon S, Reinstein DZ. Avoiding serious corneal complications of laser assisted in situ keratomileusis and photorefractive keratectomy. Ophthalmology 2000; 107(4):640-52.

[45] Rasik B Vajpayee, Namrata Sharma, Samir A Melki, Laurence Sullivan, Editors : Step by Step LASIK Surgery, published in the Taylor \& Francis e-Library, 2006, p.87-111.

[46] Buratto L, Brint SF, Ferrari M. Editors: LASIK Techniques, Thorofare, NJ, Slack Incorporated, 1998; chapter 6, p.73-99

[47] Holladay JT, Dudeja DR, Chang J. Functional vision and corneal changes after laser in situ keratomileusis determined by contrast sensitivity, glare testing, and corneal topography. J Cataract Refract Surg. 1999;25:663-669.

[48] Pe'rez-Santonja JJ, Bellot J, Claramonte P, et al. Laser in keratomileusis to correct high myopia. J Cataract Refract Surg. 1997;23:372-385.

[49] Nadia-Marie Quesnel, John V Lovasik, Christian Ferremi et al, Laser in situ keratomileusis for myopia and the contrast sensitivity function, J Cataract Refract Surg June 2004; Vol30, Issue 6:1209-1218.

[50]Deirdre Townley, Caitriona Kirwan, Michael O'Keefe et al. One year follow-up of contrast sensitivity following conventional laser in situ keratomileusis and laser epithelial keratomileusis, Acta Ophthalmologica, Volume 90, Issue 1, pages 81-85, February 2012.

[51] Tetsuro Oshika, Tadatoshi Tokunaga, Tomokazu Samejima, et al. Influence of Pupil Diameter on the Relation between Ocular Higher-Order Aberration and Contrast Sensitivity after Laser In Situ Keratomileusis. Invest Ophthalmol Vis Sci. 2006;47:1334-1338, DOI:10.1167/iovs.05-1154.

[52] Prema Padmanabhan, MS, Michael Mrochen, PhD, Subam Basuthkar, et al. Wavefront-guided versus wavefront-optimized laser in situ keratomileusis: Contralateral comparative study, J Cataract Refract Surg March 2008; Vol 34:389-39.

[53] Loukotová V, Vlková E, Horácková M, Tokosová E, et al. Contrast sensitivity and higher order aberration after conventional LASIK treatment, Cesk Slov Oftalmol. 2009 Oct;65(5):167-75.

Table 1: Demographic data

\begin{tabular}{|c|c|c|}
\hline & Number & Percentage \\
\hline \multicolumn{3}{|c|}{ Sex } \\
\hline Male & 10 & $34 \%$ \\
\hline Female & 19 & $66 \%$ \\
\hline Total & 29 & $100 \%$ \\
\hline \multicolumn{3}{|c|}{ Laterality } \\
\hline Right eye & 28 & $50 \%$ \\
\hline Left eye & 28 & $50 \%$ \\
\hline Total & 56 & $100 \%$ \\
\hline
\end{tabular}




\section{International Journal of Science and Research (IJSR) \\ ISSN (Online): 2319-7064}

Index Copernicus Value (2013): 6.14 | Impact Factor (2014): 5.611

Table 2: Simulated Keratometry \& Ultrasound Pachymetry

\begin{tabular}{|c|c|c|c|}
\hline Mean & Standard Deviation & Minimum & Maximum \\
\hline \multicolumn{4}{|c|}{ Simulated Keratometry } \\
\hline 44.44 & 1.68 & 40.87 & 47.93 \\
\hline \multicolumn{4}{|c|}{ Ultrasound Pachymetry } \\
\hline 556.83 & 32.81 & 500 & 624 \\
\hline
\end{tabular}

Table 3: Change in visual acuity after LASIK (logMAR

\begin{tabular}{|c|c|c|c|}
\hline \multicolumn{4}{|c|}{ values) } \\
\hline Visit & Mean & SD & $\begin{array}{c}\text { p value } \\
\text { (by paired 't' test) }\end{array}$ \\
\hline Pre-operative (BCVA) & 0.00 & 0.0 & 0.00 \\
\hline 1 month (UCVA) & -0.096 & 0.0 & 0.00 \\
\hline 3 months (UCVA) & -0.096 & 0.0 & 0.00 \\
\hline 6 months (UCVA) & -0.096 & 0.0 & 0 \\
\hline
\end{tabular}

(BCVA: Best corrected visual acuity; UCVA: Uncorrected visual acuity)

Table 4: Change in refractive error (Spherical Equivalent in Dioptre)

\begin{tabular}{|c|c|c|c|}
\hline Visit & Mean & SD & \multirow{2}{*}{$\begin{array}{c}\text { p value } \\
\text { (by paired ' } t \text { ' test) }\end{array}$} \\
\hline Pre-operative & -4.59 & 2.61 & 0.00 \\
\hline 1 month & -0.022 & 0.26 & 0.00 \\
\hline 3 months & -0.002 & 0.16 & 0.00 \\
\hline 6 months & -0.009 & 0.16 & 0 \\
\hline
\end{tabular}

Table 5: Change in spherical aberration $(Z 4,0)$

\begin{tabular}{|c|c|c|c|}
\hline Visit & Mean (microns) & SD & $\begin{array}{c}\text { p value } \\
\text { (by paired ' } t \text { ' test) }\end{array}$ \\
\hline Pre-operative & -0.21 & 0.15 & 0.00 \\
\hline 1 month & -0.57 & 0.48 & 0.00 \\
\hline 3 months & -0.50 & 0.50 & 0.00 \\
\hline 6 months & -0.46 & 0.50 & \\
\hline
\end{tabular}

Table 6: Change in Contrast sensitivity Values (Mean Log Values)

\begin{tabular}{|c|c|c|c|c|}
\hline Contrast & \multicolumn{4}{|c|}{ Mean LOG contrast sensitivity values } \\
\hline $\begin{array}{c}\text { Sensitivity } \\
\text { (frequency) }\end{array}$ & Pre-op & 1 month & 3 months & 6 months \\
\hline A (3 cyc/deg) & 5.125 & $5.125(0.92)$ & $5.178(0.75)$ & $5.357(0.13)$ \\
\hline B (6 cyc/deg) & 5.767 & $5.589(0.27)$ & $5.821(0.73)$ & $6.035(0.10)$ \\
\hline C (12 cyc/deg) & 6.017 & $5.482(0.00)$ & $5.464(0.014$ & $6.053(0.91)$ \\
\hline D (18 cyc/deg) & 6.071 & $5.66(0.048)$ & $5.964(0.52)$ & $6.053(0.93)$ \\
\hline
\end{tabular}

(Figures in parenthesis are $\mathrm{p}$ values as determined by the

Paired T test. Statistically significant values are in bold type) 